Rapid Communications

\title{
Sensitive Electrochemical Detection of the Hydroxyl Radical Using Enzyme-catalyzed Redox Cycling
}

\author{
Hirosuke TATSUMI ${ }^{* \dagger}$ and Naoya OSAKU** \\ *International Young Researchers Empowerment Center, Shinshu University, Matsumoto, Nagano 390-8621, \\ Japan \\ **Department of Chemistry, Faculty of Science, Shinshu University, Matsumoto, Nagano 390-8621, Japan
}

\begin{abstract}
Enzyme-catalyzed signal amplification was introduced to the electrochemical detection of the $\mathrm{OH}$ radical. In the presence of phenol as a trapping agent, glucose as a substrate, and pyrroloquinoline quinone-containing glucose dehydrogenase (PQQ-GDH) as a catalyst, the current signal for the trapping adducts (catechol and hydroquinone) produced by the hydroxylation of phenol could be amplified and detected sensitively. The limit of detection $(S / N=3)$ for catechol was $8 \mathrm{nM}$. The trapping efficiency of phenol was also estimated.
\end{abstract}

(Received September 29, 2011; Accepted October 3, 2011; Published November 10, 2011)

The hydroxyl $(\mathrm{OH})$ radical is known to be the most reactive oxygen radical. In living systems, it is generated by aerobic metabolism or metal-catalyzed reactions, and plays important roles in physiological processes. Because of the high reactivity and the short lifetime, any direct measurement of the $\mathrm{OH}$ radical is very difficult. Instead, numerous reports have appeared on indirect $\mathrm{OH}$ radical detection by trapping reactions, in which the $\mathrm{OH}$ radical provides stable adducts with aromatic compounds or spin-trapping agents. ${ }^{1} \quad$ When aniline, phenol, and their derivatives are used as trapping agents, those adducts with the aminophenol, catechol, or hydroquinone structure are produced by hydroxylation, which allows for a simple detection system based on electrochemical oxidation..$^{2-4}$ Liquid chromatography with electrochemical detection using these aromatic trapping agents has been one of the most widely used methods for $\mathrm{OH}$ radical detection so far. ${ }^{1}$ However, the concentration of the $\mathrm{OH}$ radical in vivo is extremely low, ${ }^{1}$ and thus an electrochemical method for a highly sensitive determination of $\mathrm{OH}$ trapping adducts has been desired. ${ }^{5}$

Signal amplification in amperometry and voltammetry using enzyme-catalyzed redox cycling, in which an analyte is reproduced with the aid of a redox enzyme, has been extensively studied by many researchers. ${ }^{6-12}$ This technique has been applied to sensitive detection in enzyme immunoassay ${ }^{8,9,11}$ and enzyme-linked DNA hybridization assay. ${ }^{10,12}$ However, it has not been applied to $\mathrm{OH}$ radical detection. In this communication, we present our electrochemical detection of the $\mathrm{OH}$ radical using an enzyme-catalyzed signal amplification system. In the presence of phenol as a trapping agent, glucose as a substrate, and pyrroloquinoline quinone-containing glucose dehydrogenase (PQQ-GDH) as a catalyst, the current signal for the trapping adducts (catechol and hydroquinone) produced by the hydroxylation of phenol could be amplified and detected sensitively.

The $\mathrm{OH}$ radical was generated and trapped according to

† To whom correspondence should be addressed.

E-mail: tatsumi@shinshu-u.ac.jp
$\mathrm{Hu}$ et al.'s method with the $[\mathrm{Fe}(\mathrm{II}) \mathrm{EDTA}]^{2-} \quad(\mathrm{EDTA}=$ ethylenediamine tetraacetate) complex. ${ }^{5} \mathrm{H}_{2} \mathrm{O}_{2}(0.20-2.0 \mathrm{mM})$ was added into a pH 7.0 phosphate buffer containing $0.20-2.0 \mathrm{mM}$ [Fe(II)EDTA $]^{2-}, \quad 0.20-2.0 \mathrm{mM}$ phenol, and $0.10 \mathrm{M}$ glucose. The voltammetric currents of the trapping adducts (catechol and hydroquinone) produced by the hydroxylation of phenol were recorded in both the presence and absence of $10 \mathrm{U} \mathrm{mL}^{-1}$ PQQ-GDH (Toyobo, Japan). In voltammetric measurements, a plastic-formed carbon (PFC) disk electrode (BAS Cat. No. 002408) was used as the working electrode. The geometric surface area of the PFC electrode was $0.071 \mathrm{~cm}^{2}$. A platinum coil and an $\mathrm{Ag} / \mathrm{AgCl}(0.1 \mathrm{M} \mathrm{KCl})$ electrode were used as the counter electrode and the reference electrode, respectively. Current $v s$. applied potential $(I-E)$ curves were recorded by a laboratory-made electrochemical analyzer. All of the experiments were performed at $25 \pm 1{ }^{\circ} \mathrm{C}$.

The curve a (broken line) in Fig. 1A shows a cyclic voltammogram of the buffer containing $2.0 \mathrm{mM}$ [Fe(II)EDTA $]^{2-}$, $2.0 \mathrm{mM}$ phenol, and $0.10 \mathrm{M}$ glucose at $v=5 \mathrm{mV} \mathrm{s}^{-1}$. Neither $[\mathrm{Fe}(\mathrm{II}) \mathrm{EDTA}]^{2-}$ nor phenol gave an oxidation wave within the potential range between -100 and $300 \mathrm{mV}$. Upon the addition of $2.0 \mathrm{mM} \mathrm{H}_{2} \mathrm{O}_{2}$ into the solution, a pair of small anodic and cathodic peak currents were observed at about $100 \mathrm{mV}$, besides the direct reduction of $\mathrm{H}_{2} \mathrm{O}_{2}$ at about $-100 \mathrm{mV}$ (curve $\mathrm{b}$, thin line). The midpoint potentials of catechol and hydroquinone were determined to be 92 and $-22 \mathrm{mV}$, respectively, by separate experiments of cyclic voltammetry, indicating that catechol was the predominant detectable hydroxylated adduct by trapping the $\mathrm{OH}$ radical. When $10 \mathrm{U} \mathrm{mL}^{-1} \mathrm{PQQ}-\mathrm{GDH}$ was added into the solution, an amplified oxidation current appeared, as shown in curve $\mathrm{c}$ in Fig. 1A (bold line). This can be mainly ascribed to the electrochemical oxidation of catechol coupled with the regeneration of catechol by the PQQ-GDH-catalyzed reduction of $o$-quinone in the presence of glucose. A small current increase at about $0 \mathrm{mV}$ may be derived from a small production of hydroquinone. Figure $1 \mathrm{~B}$ was obtained with lower concentrations of [Fe(II)EDTA ${ }^{2-}$, phenol, and $\mathrm{H}_{2} \mathrm{O}_{2}(0.20 \mathrm{mM}$ each). While the pair of anodic and cathodic peak currents was 

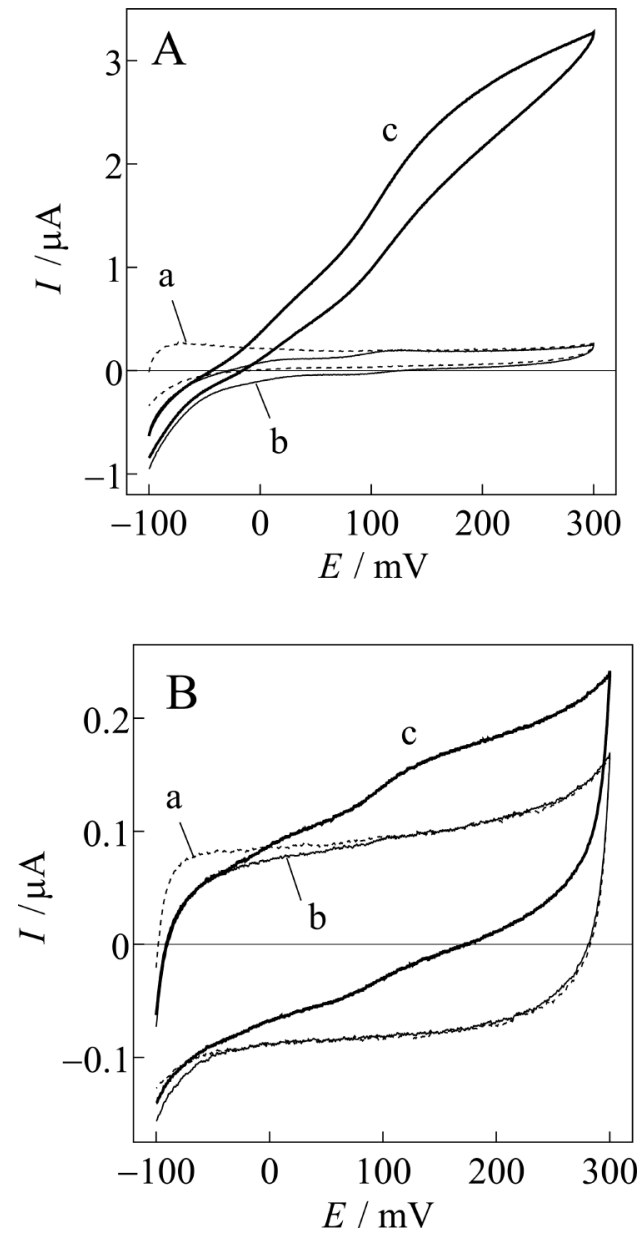

Fig. 1 (A) Cyclic voltammograms of a $\mathrm{pH} 7.0$ phosphate buffer containing $2.0 \mathrm{mM}[\mathrm{Fe}(\mathrm{II}) \mathrm{EDTA}]^{2-}, 2.0 \mathrm{mM}$ phenol, and $0.10 \mathrm{M}$ glucose at $v=5 \mathrm{mV} \mathrm{s}^{-1}$ (a) before the addition of $\mathrm{H}_{2} \mathrm{O}_{2}$, (b) after the addition of $2.0 \mathrm{mM} \mathrm{H}_{2} \mathrm{O}_{2}$, and (c) after the addition of $10 \mathrm{U} \mathrm{mL}^{-1}$ PQQ-GDH. (B) Same as (A), except that the concentrations of [Fe(II)EDTA] $]^{2-}$, phenol, and $\mathrm{H}_{2} \mathrm{O}_{2}$ are $0.20 \mathrm{mM}$.

no longer observed before the addition of PQQ-GDH (curve b, thin line), the catalytic oxidation current was clearly observed after the addition of PQQ-GDH (curve c, bold line). Figure 2A shows linear-sweep voltammograms (after subtraction of the background current) of various concentrations of catechol in a buffer containing $0.10 \mathrm{M}$ glucose and $10 \mathrm{U} \mathrm{mL}^{-1}$ PQQ-GDH at $v=5 \mathrm{mV} \mathrm{s}^{-1}$. The limiting catalytic current $\left(I_{\mathrm{lim}}\right)$ obtained at $E=280 \mathrm{mV}$ was proportional to the concentration of catechol $(C)$, as shown in Fig. 2B. This result indicates that $C$ is sufficiently lower than the Michaelis constant $\left(K_{\mathrm{M}}\right)$, and thus $I_{\text {lim }}$ can be related to $C$ by the following equation: ${ }^{13}$

$$
I_{\lim }=n F q C \sqrt{D \frac{k_{\mathrm{cat}}}{K_{\mathrm{M}}}[\mathrm{E}]},
$$

where $D$ is the diffusion coefficient of catechol, $k_{\text {cat }}$ is the turnover number of the enzyme reaction, [E] is the molar concentration of the enzyme; $n, F$ and $q$ are the number of electrons at the electrode reaction (here, $n=2$ ), the Faraday constant, and the electrode surface area, respectively. $D$ was estimated to be $7.7 \times 10^{-6} \mathrm{~cm}^{2} \mathrm{~s}^{-1}$ by the cyclic voltammetry of catechol in the absence of glucose and PQQ-GDH. The limit of detection $(S / N=3)$ of $8 \mathrm{nM}$ and $k_{\text {cat }} / K_{\mathrm{M}}$ of $2.7 \times 10^{9} \mathrm{M}^{-1} \mathrm{~s}^{-1}$
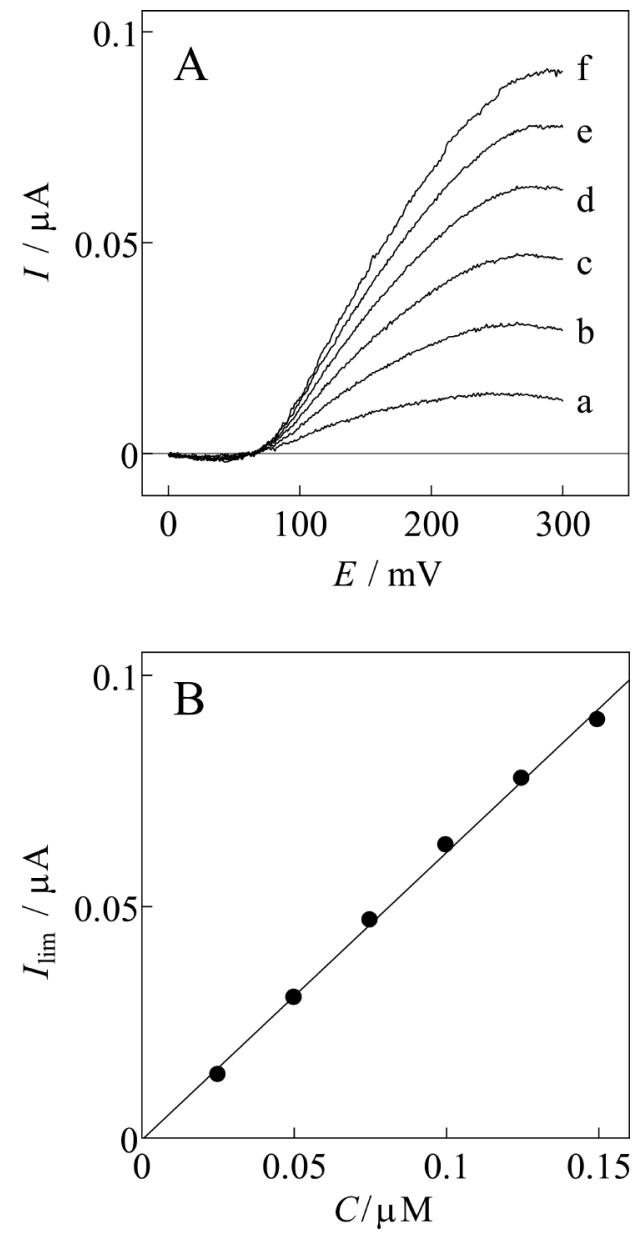

Fig. 2 (A) Linear-sweep voltammograms of catechol with $0.10 \mathrm{M}$ glucose and $10 \mathrm{U} \mathrm{mL}^{-1}$ PQQ-GDH after subtracting the background current. $C=$ (a) 0.025 , (b) 0.050 , (c) 0.075 , (d) 0.100, (e) 0.125, (f) $0.150 \mu \mathrm{M}$. Scan rate, $v=5 \mathrm{mV} \mathrm{s}^{-1}$. (B) Plot of $I_{\lim }$ against $C$. The solid line is the regression line.

were obtained from the regression line in Fig. 2B. This $k_{\mathrm{cat}} / K_{\mathrm{M}}$ value agreed with the reported values in the order of $10^{9}-10^{10} \mathrm{M}^{-1} \mathrm{~s}^{-1}$ for various quinone compounds. ${ }^{14} \mathrm{We}$ determined the concentration of catechol produced by the hydroxylation of phenol in Fig. 1B to be $0.12 \mu \mathrm{M}$, on the assumption that the production of hydroquinone was negligible. Here, we define the trapping efficiency (TE) as

$$
\mathrm{TE}=\frac{C_{\text {add }}}{C_{\mathrm{OH} \max }},
$$

where $C_{\text {add }}$ is the concentration of the hydroxylated adduct (here, catechol), and $C_{\mathrm{OH} \max }$ is the supposed maximum concentration of the $\mathrm{OH}$ radical generated in the system (here, $C_{\mathrm{OHmax}}=$ $0.20 \mathrm{mM}$, assuming that $[\mathrm{Fe}(\mathrm{II}) E D T A]^{2-}$ and $\mathrm{H}_{2} \mathrm{O}_{2}$ react stoichiometrically). By Eq. (2), the TE was estimated to be $0.06 \%$. This TE value is much lower than the reported value of $7 \%$ for the production of catechol by mixing a Fe(II)-ADP ( $\mathrm{ADP}=$ adenosine diphosphate) complex and $\mathrm{H}_{2} \mathrm{O}_{2}$ with phenol at $\mathrm{pH} 7.2,37^{\circ} \mathrm{C},{ }^{3}$ probably due to the difference in the $\mathrm{Fe}(\mathrm{II})$ complex and the temperature. No significant effect of inactivation of PQQ-GDH was observed with $2.0 \mathrm{mM}$ or lower concentrations of phenol during the course of the experiment. However, PQQ-GDH was considerably inactivated 
when $10 \mathrm{mM}$ phenol was used.

If a phenolic trapping agent has a substituent group at the para-position, we can expect only one detectable hydroxylated adduct (i.e., catechol form) by trapping the $\mathrm{OH}$ radical, which leads to a more accurate determination of the adduct. We are now trying to find a para-substituted phenolic compound that gives high amplification and trapping efficiency without any effect due to inactivation of the enzyme.

\section{Acknowledgements}

This study was initiated by a discussion with Prof. Jiye Jin (Shinshu University), to whom the authors are deeply grateful. This study was performed through a Grant-in-Aid for Young Scientists (No. 23760746) and Special Coordination Funds for Promoting Science and Technology of the Ministry of Education, Culture, Sports, Science and Technology, the Japanese Government.

\section{References}

1. F.-C. Cheng, J.-F. Jen, and T.-H. Tsai, J. Chromatogr., B, 2002, 781, 481.

2. D. M. Radzik, D. A. Roston, and P. T. Kissinger, Anal. Biochem., 1983, 131, 458.
3. R. A. Floyd, J. J. Watson, and P. K. Wong, J. Biochem. Biophys. Methods, 1984, 10, 221.

4. M. Grootveld and B. Halliwell, Biochem. J., 1986, 237, 499.

5. Y.-L. Hu, Y. Lu, G.-J. Zhou, and X.-H. Xia, Talanta, 2008, 74, 760 .

6. F. Mizutani, S. Yabuki, and M. Asai, Biosens. Bioelectron., 1991, 6, 305

7. A. L. Ghindilis, A. Makower, C. G. Bauer, F. F. Bier, and F. W. Scheller, Anal. Chim. Acta, 1995, 304, 25.

8. C. G. Bauer, A. V. Eremenko, E. Ehrentreich-Förster, F. F. Bier, A. Makower, H. B. Halsall, W. R. Heineman, and F. W. Scheller, Anal. Chem., 1996, 68, 2453.

9. S. Ito, S. Yamazaki, K. Kano, and T. Ikeda, Anal. Chim. Acta, 2000, 424, 57.

10. B. Y. Won, H. C. Yoon, and H. G. Park, Analyst, 2008, 131, 100

11. Y. Yuan, R. Yuan, Y. Chai, Y. Zhuo, L. Bai, and Y. Liao, Anal. Biochem., 2010, 405, 121.

12. Z. Zhang, J. Zhou, A. Tang, Z. Wu, G. Shen, and R. Yu, Biosens. Bioelectron., 2010, 25, 1953.

13. Y. Ogino, K. Takagi, K. Kano, and T. Ikeda, J. Electroanal. Chem., 1995, 396, 517.

14. N. Okumura, T. Abo, S. Tsujimura, and K. Kano, Electrochemistry, 2006, 74, 639. 